\title{
An image analysis of the spatial distribution of perivascular mast cells in human melanoma
}

\author{
DIEGO GUIDOLIN ${ }^{1}$, ENRICO CRIVELLATO ${ }^{2}$, BEATRICE NICO $^{3}$, \\ PAOLA G. ANDREIS ${ }^{1}$, GASTONE G. NUSSDORFER ${ }^{1}$ and DOMENICO RIBATTI ${ }^{3}$ \\ ${ }^{1}$ Department of Human Anatomy and Physiology, Section of Anatomy, University of Padua Medical School, Padua; \\ ${ }^{2}$ Department of Medical and Morphological Sciences, Section of Anatomy, University of Udine Medical School, Udine; \\ ${ }^{3}$ Department of Human Anatomy and Histology, University of Bari Medical School, Bari, Italy
}

Received August 25, 2005; Accepted October 17, 2005

\begin{abstract}
A mutual spatial and functional relationship occurs between mast cells (MCs) and endothelial cells and the density of MCs is highly correlated with the extent of tumor angiogenesis. The aim of this study was to investigate the pattern of MCs around the blood vessels in melanoma samples by means of an approach derived from spatial statistics, based on the analysis of the distribution of the distances of MCs from vessels to objectively establish if the two structures (MCs and vessels) are distributed independently over the studied area or if they displayed any kind of spatial association. Results showed that a higher number of vessels and MCs can be observed in melanoma as compared with samples from common acquired nevi (control group). The percent of area covered by vessel profiles was significantly higher in the melanoma group than the control group and the MC density was also significantly different; the melanoma group showing a number of MCs per unit area twice as high as the number measured in the control group. Furthermore, in the melanoma group, MCs were closer to each other and to the vessels. In fact, both the mean distance from vessels and the mean distance from the nearest cell profile were significantly lower than in the control group. This close association between MCs and the endothelium does not necessarily imply a participation of MCs in angiogenic processes, but might rather indicate that MCs are involved in the maintenance reaction necessary for the long lasting functional integrity of the endothelium.
\end{abstract}

\section{Introduction}

In solid tumor growth, a specific critical turning point is the transition from the avascular to the vascular phase (1). Having

Correspondence to: Professor Domenico Ribatti, Department of Human Anatomy and Histology, Policlinico, Piazza Giulio Cesare 11, I-70124 Bari, Italy

E-mail: ribatti@anatomia.uniba.it

Key words: angiogenesis, image analysis, mast cells, melanoma developed an intrinsic vascular network, the neoplastic mass is able to growth indefinitely both in situ and at distant sites (metastasis) in so far as an intrinsic vascular network enables its cells to enter the vascular bed and colonize other organs (2).

Human melanoma progresses through different steps: nevocellular nevi, dysplastic nevi, in situ melanoma, radial growth phase melanoma (Breslow index $<0.75 \mathrm{~mm}$ ), vertical growth phase melanoma (Breslow index $>0.75 \mathrm{~mm}$ ) and metastatic melanoma. In agreement with progression, it acquires a rich vascular network $(3,4)$, whereas an increasing proportion of tumor cells express the laminin receptor, which enables their adhesion to the vascular wall (5).

Tumor cells are surrounded by an infiltrate of inflammatory cells, such as lymphocytes, neutrophils, macrophages and mast cells (MCs). These cells communicate by a complex network of intercellular signaling pathways mediated by surface adhesion molecules, cytokines and their receptors (6). It is becoming clear that stromal cells cooperate with endothelial and cancer cells in promoting angiogenesis. In particular, infiltrating inflammatory cells secrete a diverse repertoire of growth factors and proteases that enable them to enhance tumor growth by stimulating angiogenesis.

The density of MCs is highly correlated with the extent of both normal and pathological angiogenesis, such as that in chronic inflammatory diseases and tumors (7). In MCdeficient mice, tumor angiogenesis is reduced to significant extents (8). MCs release a variety of factors known to enhance angiogenesis; for example, heparin, histamine and angiogenic cytokines such as transforming growth factor $\beta$, tumor necrosis factor $\alpha$, interleukin- 8 , fibroblast growth factor- 2 and vascular endothelial growth factor.

Two types of human mast cell (MC) have been described on the basis of the differences in their neutral protease composition $\left(\mathrm{MC}_{\mathrm{T}}\right.$ cells, which contain tryptase only, and $\mathrm{MC}_{\mathrm{TC}}$ cells, which contain both tryptase and chymase) (9). Tryptase positivity reflects the total number of MCs, whereas chymase is not present in all MCs. Blair et al (10) have shown that tryptase released by MCs at an angiogenesis site may play an important role in neovascularization. Direct addition of tryptase to microvascular endothelial cells cultured on Matrigel caused a pronounced increase of capillary growth, which was suppressed by specific tryptase inhibitors. Also, 

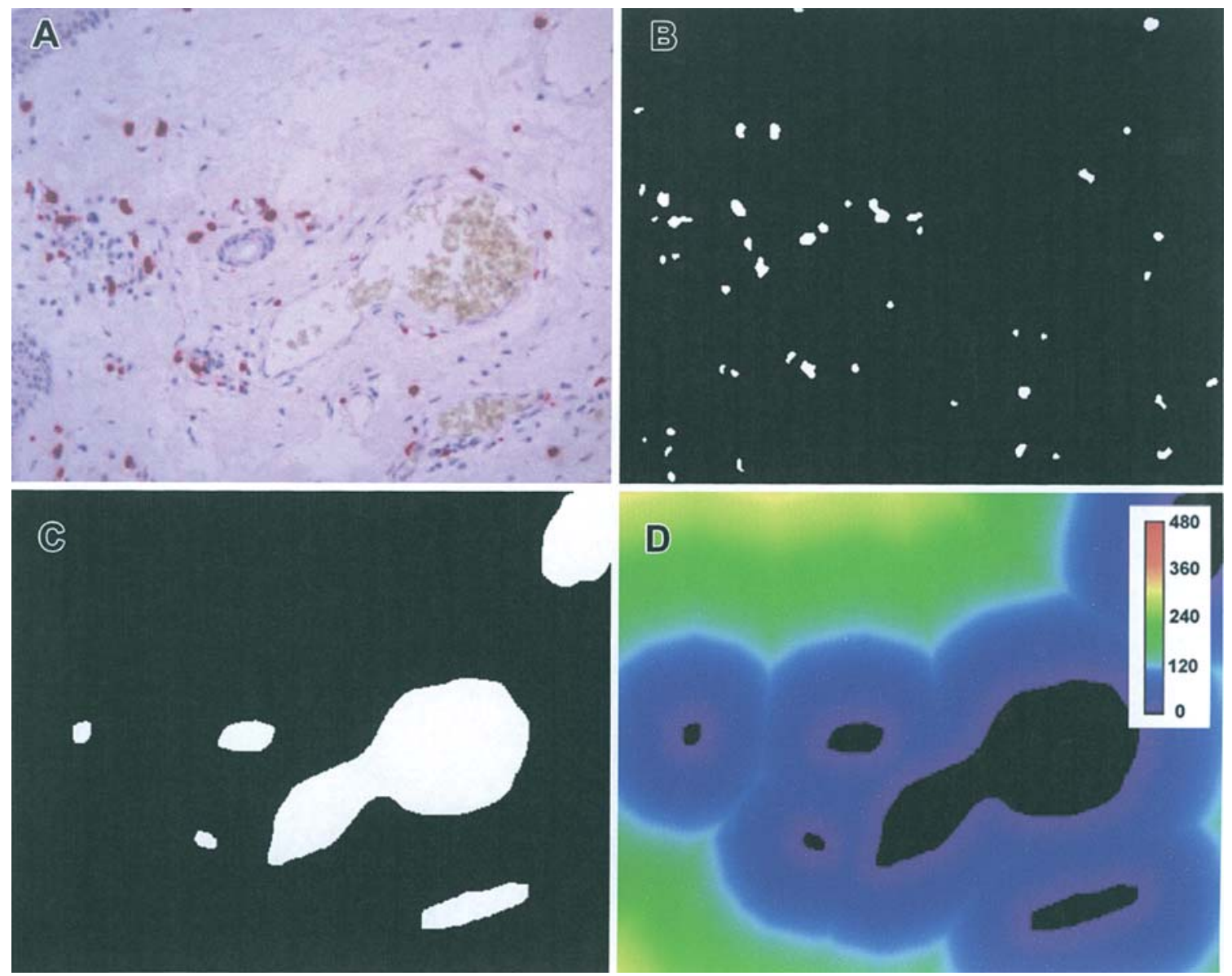

Figure 1. Main steps of the image analysis procedure. (A) Field image analysis with tryptase-positive MCs (red) and a number of transversely cut microvessels. (B) By applying a colour thresholding procedure (see text), the red-stained cell profiles were discriminated and their morphometrical parameters (profile number and $\mathrm{x}$, y-coordinates of each cell profile) were recorded. (C) Binary image of the vessel profiles obtained by interactively tracing their contour. From this image the area fraction occupied by vessels was also measured. (D) Distance transform of the image shown in C: background pixels are labeled according to their distance from the nearest vessel profile boundary. Distances are shown coded in colours as indicated by the reference scale in the upper right corner. The distance of each cell profile from the vessels can be estimated by the value of the map at the point where the cell profile is located (i.e. at its $\mathrm{x}, \mathrm{y}$-coordinates).

tryptase directly induced endothelial cell proliferation in a dose-dependent fashion.

We have previously demonstrated that, in B-cell nonHodgkin's lymphoma, myelodysplastic syndromes, B-cell chronic lymphocytic leukemia and melanoma, there is a striking association between tryptase-positive MCs and microvessel counts, and both increase in function of malignancy (11-14). Moreover, we have further demonstrated that tumor vascularity and tryptase-positive MCs correlate with a poor prognosis in melanoma (15).

The aim of this study was to investigate the pattern of tryptase-positive MCs around the blood vessels in melanoma samples by introducing a quantitative approach to characterize their spatial distribution.

\section{Materials and methods}

Tissue samples. Tissues were selected from the six clinical steps of melanoma progression described by Clark et al (16). The control group included tissue samples obtained from 15 common acquired nevi. The melanoma group included 20 advanced primary melanomas with a thickness $>1.5 \mathrm{~mm}$. The cohort included 10 men and 10 women with an age range of 30-75 years. The distribution of anatomic location of the primary tumors was as follows: trunk, ten; head and neck, five; extremity, five.

Specimens were fixed in $10 \%$ buffered-formalin and embedded in paraffin. Histological sections, $5 \mu \mathrm{m}$ thick, were prepared for immunohistochemical study.

Immunohistochemical staining. A murine monoclonal antibody against tryptase (MAb AA1, Dako) was used. Briefly, sections were collected on 3-amino-propyl-triethoxysilane-coated slides, de-paraffinized by the xylene-ethanol sequence, rehydrated in a graded ethanol scale and in Tris-buffered saline (TBS, pH 7.6) and incubated overnight at $4^{\circ} \mathrm{C}$ with AA1 (1:1500 in TBS), after prior antigen retrieval by enzymatic digestion with Ficin (Sigma, St. Louis, MO) for $30 \mathrm{~min}$ at room temperature. The immunoreaction was performed using the streptavidin-peroxidase complex (LSAB2, Dako) and Fast Red as chromogen, followed by haematoxylin counterstaining. An unrelated monoclonal IgG1 produced by the P3x63/Ag8 mouse secretory myeloma replacing the MAb served as negative control (5). 


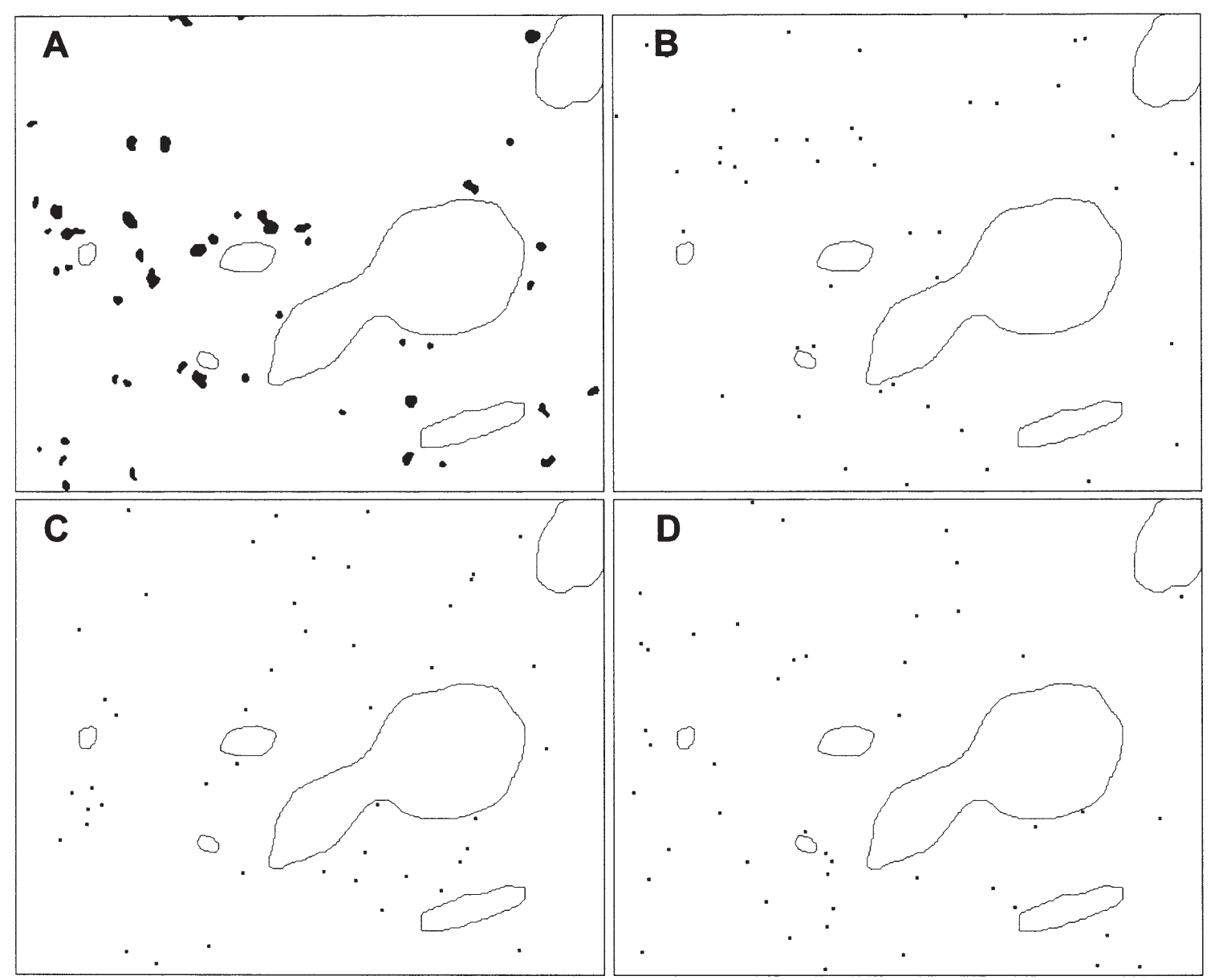

Figure 2. (A) Binary image of the cell profiles discriminated from the image shown in Fig. 1A, together with the outlines of the vessel profiles. (B-D) Three simulations of a random point pattern defined in the same area of interest and with a number of points equal to the number of cell profiles shown in (A). One hundred simulated patterns were used to estimate the distribution of the cell-to-vessel distance in the case of complete spatial randomness (see text) and its $95 \%$ confidence envelope to be used for statistical comparisons.

Image analysis methods. Computer-assisted image analysis was performed to characterize the distribution of MCs around the vessel profiles. The image analysis system included a Leica DM-R microscope (Leica Microsystems, Wetzlar, Germany) and a high-resolution digital camera (DC200, Leica Microsystems) that transmits image data to a PC equipped with appropriate software for image acquisition and analysis (QWin, Leica Microsystems, Cambridge, UK). At a primary magnification of x16, 4 fields covering the whole of each of two sections per biopsy were considered and the image of each field was acquired in full colour (24-bit), processed to correct the shading and enhance the contrast, and stored as a TIFF file.

The main steps of the image analysis procedure are illustrated in Fig. 1. The study area within the image was defined as the minimum rectangle bounding MCs and vessels. Colour thresholding was then applied for the identification of the MC profiles. According to this procedure, pixel colours were represented as HSI (hue, saturation, intensity) values (17). In general, for stains used in biological samples, the 'hue' component identifies the location of a particular stain, while the 'saturation' corresponds to the amount of staining and the 'intensity' indicates the overall density of the stained specimen. Selecting only pixels with a red hue and saturation greater than the mean saturation level exhibited by the background plus two standard deviations, a binary image containing the MC profiles only was identified (Fig. 1B). A second binary image (Fig. 1C) corresponding to the vessel profiles present in the image was also obtained by interactively tracing their contour. From these images, the number of MC profiles, their positions (i.e. $\mathrm{x}, \mathrm{y}$-coordinates of the gravity centers), the distance of each profile from its nearest neighbour and the area fraction occupied by vessels were evaluated. To estimate the distance of each MC profile from the vessels, the binary image of the vessel profiles was further processed to calculate its 'distance transform' (17). This algorithm provides a map where each background pixel is labelled (Fig. 1D) with a value equal to its distance from the nearest pixel belonging to a vessel profile. The distance from vessels of each MC profile was then evaluated by the value the map exhibited at the location corresponding to the $\mathrm{x}, \mathrm{y}$-coordinates of the cell profile.

Around the observed set of vessel profiles, 100 random (Poisson) point patterns were finally computer generated (Fig. 2). Each pattern had a number of points equal to the number of observed mast cell profiles. They underwent the previously described analysis in order to provide Monte Carlo estimates (18) of the distances from vessels in the case of complete spatial randomness (CSR). 

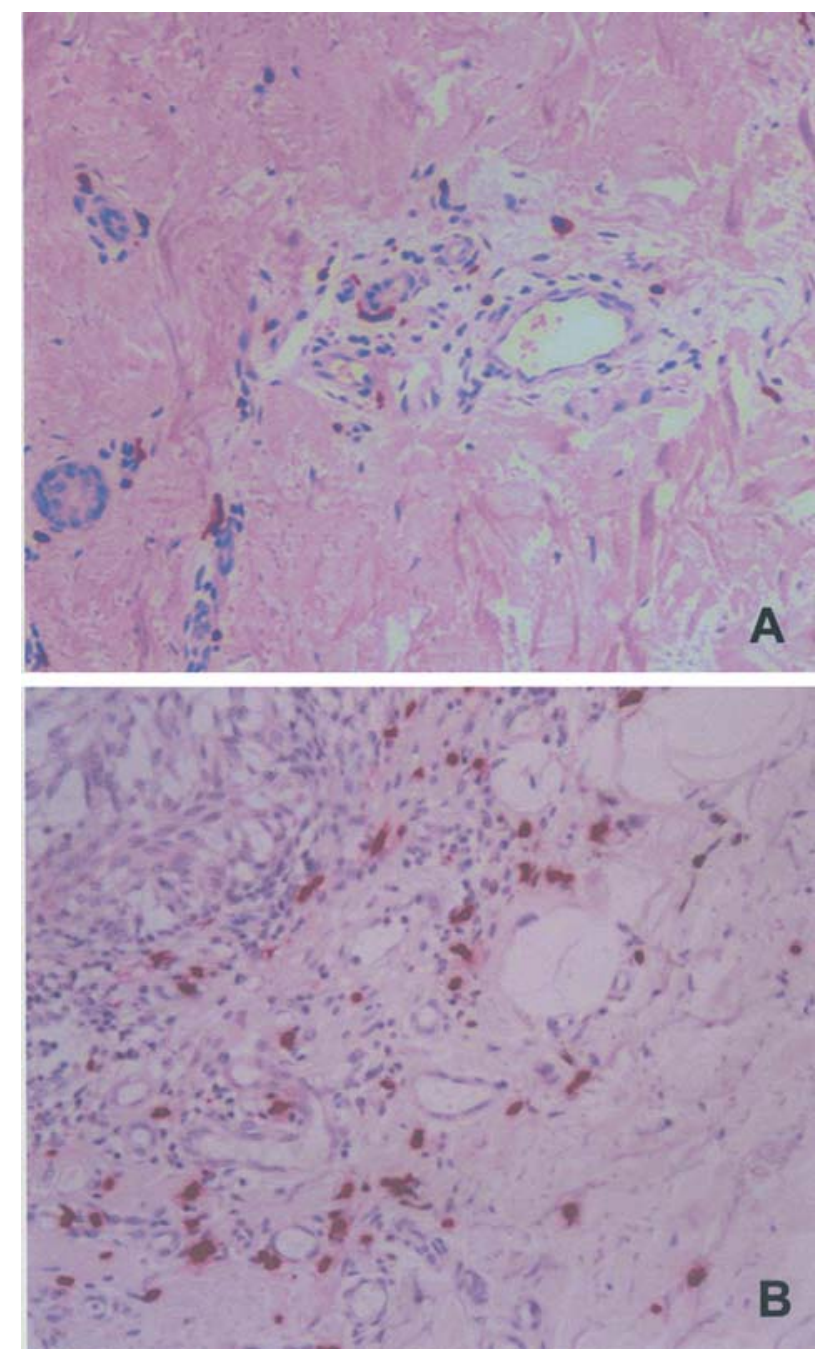

Figure 3. Histological sections of a common acquired nevus (A) and of a melanoma (B) stained with tryptase for MCs (red) and counterstained with haematoxylin. Note the higher density of MCs and of microvessels in the melanoma specimen. Original magnification, x160.

Statistics. Within each sample, MC density values (number of cells per unit area of sampled tissue), distances from the nearest neighbour and vessel area fractions were averaged to provide a representative value for that sample. Differences between the two groups of samples were then statistically tested by Student's t-test. The GraphPad Prism 3.0 statistical package (GraphPad Software Inc., San Diego CA, USA) was used for the analysis and $\mathrm{p} \leq 0.05$ was considered as the limit for statistical significance.

For each group, the cumulative frequency distribution $[\mathrm{G}(\mathrm{d})]$ of all the observed cell-to-vessel distances was calculated. Its expected value under $\operatorname{CSR}\left[\mathrm{G}_{0}(\mathrm{~d})\right]$ was estimated by averaging the cumulative frequency distributions of the distances from vessels obtained from the 100 simulated random point patterns. To interpret the cell-to-vessel spatial relationship statistically, the $95 \%$ confidence envelope for $\mathrm{G}_{0}(\mathrm{~d})$ was also calculated from the Monte Carlo simulations (19). The null hypothesis is that there is no difference between the two functions, i.e. $G(d)=G_{0}(d)$ for all d. Thus, if $G(d)$ is greater than the confidence envelope around $\mathrm{G}_{0}(\mathrm{~d})$, then the cells are clustered around the vessels, i.e. they are closer to
Table I. Tissue density of vessels and tryptase-positive cells.

\begin{tabular}{lccc}
\hline & \multicolumn{3}{c}{ Group } \\
\cline { 2 - 4 } & $\begin{array}{c}\text { Common } \\
\text { acquired nevi }\end{array}$ & $\begin{array}{c}\text { Primary } \\
\text { melanoma }\end{array}$ & p-value \\
\hline $\begin{array}{l}\text { Vessels } \\
\text { (area } \% \pm \text { SEM) }\end{array}$ & $1.41 \pm 0.27$ & $8.14 \pm 1.8$ & 0.0061 \\
$\begin{array}{l}\text { Tryptase-positive } \\
\text { cells } / \mathrm{mm}^{2}\end{array}$ & $48.5 \pm 8$ & $101.7 \pm 8$ & 0.0015 \\
\hline
\end{tabular}
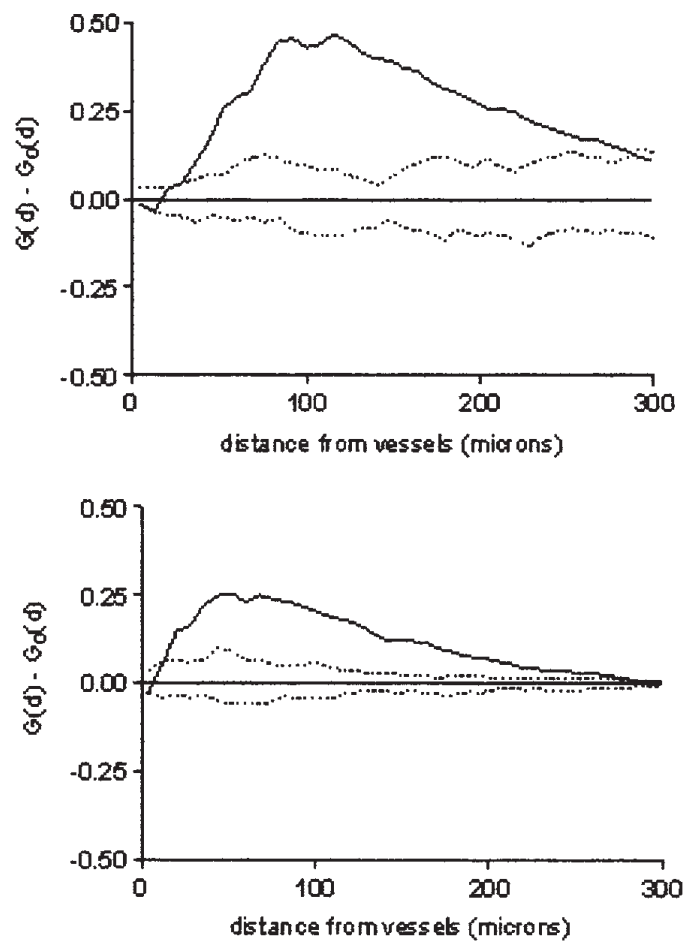

Figure 4. Analysis of the spatial relationship between MCs and microvessels. Solid lines indicate the difference between the observed distribution of cell-to-vessel distances $[\mathrm{G}(\mathrm{d})]$ and the estimated distribution $\left[\mathrm{G}_{0}(\mathrm{~d})\right]$ under complete spatial randomness (CSR). Dotted lines indicate the $95 \%$ confidence envelope for CSR. Both in the common acquired nevi group (A) and in the melanoma group (B), there is a spatial association between MCs and vessels as indicated by a frequency of short cell-to-vessel distances significantly higher than expected by chance.

the vessels than expected by chance. If $\mathrm{G}(\mathrm{d})$ is lower than the envelope around $\mathrm{G}_{0}(\mathrm{~d})$, then short cell-to-vessel distances are less frequent than expected by chance, i.e. the placement of the cells close to the vessels was 'inhibited' (20).

\section{Results}

As shown in Fig. 3, a higher number of vessels and MCs can be observed in the tissue sections from the lesions of patients with primary melanoma as compared with samples from patients with common acquired nevi (control group).

This morphological observation was confirmed by morphometric evaluation as shown in Table I. The percent 


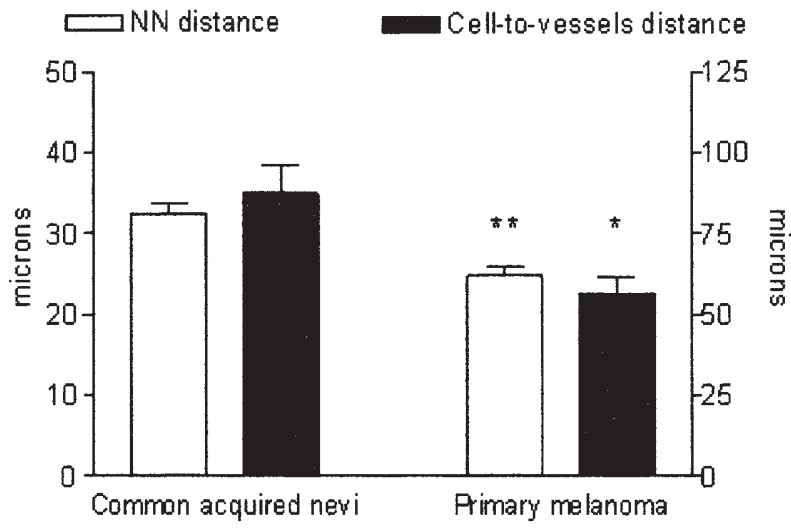

Figure 5. Mean intercellular MC distance (estimated as the distance from the nearest neighbour cell) and mean distance from vessels in the common acquired nevi group $(\mathrm{N}=15)$ and in the melanoma group $(\mathrm{N}=20)$. Error bars are SEM. ${ }^{*} \mathrm{p}<0.05 ;{ }^{* *} \mathrm{p}<0.01$ (two-sample Student's t-test).

area covered by vessel profiles was significantly higher in the melanoma group than in the common acquired nevi group $(\mathrm{p}<0.01)$. The MC density was also significantly different $(p<0.01)$ between the two tested conditions; the melanoma group showing a number of MCs per unit area twice as high as the number measured in the common acquired nevi group.

In both groups, the spatial distribution of MCs was characterized by significant deviations from randomness. In particular, the cell pattern in both cases was clumped around the vessel profiles as indicated by a G(d) significantly higher than expected under complete spatial randomness (Fig. 4). When compared to the samples from the common acquired nevi group, however, in the melanoma group, MCs were closer to each other and to the vessels. In fact, both the mean distance from vessels and the mean distance from the nearest cell profile (Fig. 5) were significantly $(\mathrm{p}<0.05$ and $\mathrm{p}<0.01$ respectively) lower in the common acquired group of tissue samples.

\section{Discussion}

MCs are widely distributed in connective tissue and there is much evidence of the mutual spatial and functional relationship occurring between MCs and endothelial cells. In many organs and under physiological conditions, numerous MCs are close to capillaries and lymphatic channels (21-23). Eady et al (21) found a direct correlation between the number of MCs and the density of blood vessels in the dermis.

A quantitative assessment of the spatial co-localization of MCs and vessels, however, has never been provided. Here, we addressed this topic by an approach derived from spatial statistics $(24,25)$. The method was based on the statistical analysis of the distribution of the distances of MCs from vessels with the aim to objectively establish whether the two structures (MCs and vessels) were distributed independently over the studied area or displayed any kind of spatial association. Such an analysis involved the comparison of the observed distribution of MC-to-vessel distances with the one corresponding to the case of complete spatial randomness, i.e. in which the MCs are distributed randomly over the studied area. To derive this reference distribution, a simulation technique was applied (18), involving the computer generation of point patterns of the same size as the observed cell pattern, but placed in the area under investigation according to a random (Poisson) distribution. Analyses very similar from a statistical point of view were recently applied to characterize the degree of spatial association between cell populations (26), the co-localization of immunogold labels (20) and the spatial relationship between microdomains in the plasma membrane (27). The main difference between these approaches and the method proposed here is that, in the present study, one of the two structures (i.e. the vessels) was not modelled as a point pattern but as a set of surfaces. As a consequence, distances from each cell to the nearest vessel profile boundary (roughly corresponding to the endothelial lining) were considered for the analysis. The results showed that, in both experimental groups evaluated in the present study, the spatial distribution of MCs was characterized by a significant spatial association between MCs and vessels, as indicated by a frequency of short distances higher then expected under the hypothesis of a random spatial distribution of cells.

This anatomical association between MCs and the endothelium, however, does not necessarily imply the participation of MCs in angiogenic processes, but might rather indicate that these cells are involved in the maintenance reaction necessary for the long lasting functional integrity of the endothelium (28).

Human dermal endothelial cells express the MC growth and chemotactic factor stem cell factor (SCF) $(29,30)$. Mierke et al (31) found that MCs survive for many weeks in the absence of any exogenous growth factor if cultured on an endothelial cell layer. Endothelial cell-dependent MC survival is mediated by SCF and adhesion molecules, such as vascular cell adhesion molecule-1 (VCAM-1). Furthermore, SCF induce uPAR-expression in MCs, and cells stimulated in this way could also chemotactically respond to uPA released by endothelial cells (32). These findings suggest that, under physiological conditions, endothelial cells play an important role in regulating MC influx as well as MC development and function in tissue.

MCs have been linked for almost three decades to neovascularization. Several lines of evidence have implicated MCs in the regulation of pathological or physiological examples of angiogenesis, including that associated with haemangiomas (33), tumors (7), rheumatoid arthritis (34), nasal polyps (35), wound healing (36) and ovulation (37). We have previously demonstrated that, in B-cell non-Hodgkin's lymphoma, myelodysplastic syndromes, B-cell chronic lymphocytic leukemia and melanoma, there is a striking association between tryptasepositive MCs and microvessel counts, and both increase in function of malignancy (11-15).

Here, we demonstrate that a higher number of vessels and MCs can be observed in tissue sections from the lesions of patients with primary melanoma as compared with samples from common acquired nevi (control group). In fact, the percent area covered by vessel profiles was significantly higher in the melanoma group than in the common acquired nevi group and the MC density was also significantly different; the melanoma group showing a number of MCs per unit area twice as high as the number measured in the common acquired nevi group. Furthermore, in the melanoma group, MCs were 
closer to each other and to the vessels. In fact, both the mean distance from vessels and the mean distance from the nearest cell profile were significantly lower than in the common acquired nevi group of tissue samples. Shorter intercellular distances and lower cell-to-vessel distances could be a morphological condition important to the increases in the rate of signal exchange among the cells and vessels, and to the induction of higher concentrations of signalling molecules in the pericellular and periendothelial environment.

All of these findings indicate that MCs may enhance angiogenesis, at least in the tumor model, and the preferential localization of MCs along blood vessels and sites of new vessel formation sustains the suggestion for an association between MCs and angiogenesis. It is possible, however, that the spatial association between vessels and MCs simply reflects migrating MCs from the blood stream at vessel growing sites (38). Until further data are available, the question as to whether MCs are main factors or innocent bystanders in this process will remain unsolved.

\section{Acknowledgements}

This study was supported by the Associazione Italiana per la Ricerca sul Cancro (AIRC), Milan, Ministero dell'Istruzione, dell'Università e della Ricerca (FIRB), Rome, Fondazione Italiana per la Lotta al Neuroblastoma, Genoa, Ministero della Salute (Ricerca Finalizzata FSN 2002), Rome, Italy.

\section{References}

1. Folkman J: What is the evidence that tumors are angiogenesis dependent? J Natl Cancer Inst 82: 4-6, 1990.

2. Fidler IM: Regulation of neoplastic angiogenesis. J Natl Cancer Inst Monogr 28: 10-14, 2000.

3. Barnhill RL, Fandrey K, Levy MA, Wihm MC and Hyman B: Angiogenesis and tumour progression of melanoma: quantification of vascularity in melanocytic nevi and cutaneous malignant melanoma. Lab Invest 67: 331-337, 1992.

4. Ribatti D, Vacca A, Palma W, Lospalluti M and Dammacco F: Angiogenesis during tumour progression in human malignant melanoma. In: Angiogenesis: Key Principle-Science-TechnologyMedicine. Steiner R, Weisz PB and Langer R (eds). Birkhauser, Basel, pp415-420, 1992.

5. Vacca A, Ribatti D, Roncali L, Lospalluti M, Serio G and Carrel S: Melanocyte tumor progression is associated with changes in angiogenesis and expression of the 67-kilodalton laminin receptor. Cancer 72: 455-461, 1993.

6. Park CC, Bissell MJ and Barcellos-Hoff MH: The influence of the microenvironment on the malignant phenotype. Mol Med Today 6: 324-329, 2000

7. Ribatti D, Crivellato E, Roccaro AM, Ria R and Vacca A: Mast cell contribution to angiogenesis related to tumor progression. Clin Exp Allergy 34: 1660-1664, 2004.

8. Starkey JR, Crowle PK and Taubenberger S: Mast-cell-deficient $\mathrm{W} / \mathrm{W}$ mice exhibit a decreased rate of tumor angiogenesis. Int $\mathbf{J}$ Cancer 42: 48-52, 1988.

9. Irani AM, Bradford TR, Kepley CL, Schechter NM and Schwartz LB: Detection of MCT and MCTC types of human mast cells by immunohistochemistry using new monoclonal antitryptase and anti-chymase antibodies. J Histochem Cytochem 37: 1509-1515, 1989.

10. Blair RJ, Meng H, Marchese MJ, Ren S, Schwartz LB, Tonnesen MG and Gruber BL: Human mast cells stimulate vascular tube formation. Tryptase is a novel, potent angiogenic factor. J Clin Invest 99: 2691-2700, 1997.

11. Ribatti D, Vacca A, Marzullo A, Nico B, Ria R, Roncali L and Dammacco F: Angiogenesis and mast cell density with tryptase activity increase simultaneously with pathological progression in B-cell non-Hodgkin's lymphomas. Int J Cancer 85: 171-175, 2000 .
12. Ribatti D, Polimeno G, Vacca A, Marzullo A, Crivellato E, Nico B, Lucarelli G and Dammacco F: Correlation of bone marrow angiogenesis and mast cells with tryptase activity in myelodysplastic syndromes. Leukemia 16: 1680-1684, 2002.

13. Ribatti D, Molica S, Vacca A, Nico B, Crivellato E, Roccaro AM and Dammacco F: Tryptase positive mast cells correlate positively with bone marrow angiogenesis in B-cell chronic lymphocytic leukemia. Leukemia 17: 1428-1430, 2003.

14. Ribatti D, Vacca A, Ria R, Marzullo A, Nico B, Filotico R, Roncali L and Dammacco F: Neovascularization, expression of fibroblast growth factor-2, and mast cell with tryptase activity increase simultaneously with pathological progression in human malignant melanoma. Eur J Cancer 39: 666-675, 2003.

15. Ribatti D, Ennas MG, Vacca A, Ferelli F, Nico B, Orru S and Sirigu P: Tumor vascularity and tryptase positive-mast cells correlate with a poor prognosis in melanoma. Eur J Clin Invest 33: 420-425, 2003.

16. Clark WH Jr, Elder DE, Guerry DJV, Epstein MN, Greene MH and van Horn M: A study of tumor progression: the precursor lesions of superficial spreading and nodular melanoma. Hum Pathol 15: 1146-1165, 1984.

17. Russ JC: The Image Processing Handbook. CRC Press, Boca Raton, p272, 1995.

18. Besag J and Diggle PJ: Simple Monte Carlo tests for spatial pattern. Appl Stat 26: 327-333, 1997.

19. Gatrell AC, Bailey TC, Diggle PJ and Rowlingson BS: Spatial point pattern analysis and its application in geographical epidemiology. Trans Inst Br Geogr 21: 256-274, 1996.

20. Philimonenko AA, Janàcek J and Hozàk P: Statistical evaluation of colocalization patterns in immunogold labeling experiments. J Struct Biol 132: 201-210, 2000.

21. Eady RA, Cowen T, Marshall TF, Plummer V and Greaves MW: Mast cell population density, blood vessel density and histamine content in normal human skin. Br J Dermatol 100: 623-633, 1979.

22. Rhodin JAG and Fujita H: Capillary growth in the mesentery of normal young rats. Intravital video and electron microscope analysis. J Submicrosc Cytol Pathol 21: 1-34, 1989.

23. Rakusan S, Sarkar K, Turek Z and Wickler P: Mast cells in the rat heart during normal growth and in cardiac hypertrophy. Circ Res 66: 511-516, 1990.

24. Ripley BD: Tests for randomness for spatial point patterns. J R Statist Soc B41: 368-374, 1979.

25. Diggle PJ: Statistical Analysis of Spatial Point Patterns. Academic Press, London, p354, 1983.

26. Cotter D, MacKay D, Chana G, Beasley C, Landau S and Everall IP: Reduced neuronal size and glial cell density in area 9 of the dorsolateral prefrontal cortex in subjects with major depressive disorders. Cereb Cortex 12: 386-394, 2002.

27. Prior IA, Muncke C, Parton RG and Hancock JF: Direct visualization of Ras proteins in spatially distinct cell surface microdomains. J Cell Biol 160: 165-170, 2003.

28. Watanabe Y, Lee SW, Detmar M, Ajoka I and Dvorak HF: Vascular permeability factor/vascular endothelial growth factor (VPF/VEGF) delays and induces escape from senescence in human dermal microvascular endothelial cells. Oncogene 14: 2025-2032, 1997.

29. Nilsson G, Butterfield JH, Nilsson K and Siegbahn A: Stem cell factor is a chemotactic factor for human mast cells. J Immunol 153: 3717-3723, 1994.

30. Meininger CJ and Zetter BR: Mast cells and angiogenesis. Semin Cancer Biol 3: 73-79, 1995.

31. Mierke CT, Ballmaier M, Werner U, Manns MP, Welte K and Bischoff SC: Human endothelial cells regulate survival and proliferation of human mast cells. J Exp Med 192: 801-806, 2000 .

32. Sillaber C, Baghestanian M, Hofbauser R, Virgolini I, Bankl HC, Fureder W, Agis H, Willheim M, Leimer M, Scheiner O, Binder BR, Kiener HP, Bevec D, Fritsch G, Majdic O, Kress HG, Gadner H, Lechner K and Valent P: Molecular and functional character-ization of the urokinase receptor in human mast cells. J Biol Chem 272: 7824-7832, 1997.

33. Qu Z, Liebler JM, Powers MR, Galey T, Ahmadi P, Huang XN, Ansel JC, Butterfield JH, Planck SR and Rosenbaum JY: Mast cells are a major source of basic fibroblast growth factor in chronic inflammation and cutaneous hemangioma. Am J Pathol 147: 564-573, 1995

34. Yamada T, Sawatsubashi M, Yakushiji H, Itoh Y, Edakuni G, Mori M, Robert L and Miyazaki K: Localization of vascular endothelial growth factor in synovial membrane mast cells: examination with 'multi-labelling substraction immunostaining'. Virchows Arch 433: 567-570, 1998. 
35. Vento SI, Wolff CH, Salven PJ, Hytonen ML, Ertama LO and Malmberg CH: Vascular permeability factor/vascular endothelial growth factor in nasal polyps. Acta Otolaryngol Suppl 543: 1701-1774, 2000

36. Trabucchi E, Radelli E, Marazzi M, Foschi D, Musazzi M, Veronesi AM and Montorsi W: The role of mast cells in wound healing. Int J Tissue React 10: 367-372, 1988.
37. Kirshna A, Beesley K and Terranova PF: Histamine, mast cells and ovarian function. J Endocrinol 120: 363-371, 1989.

38. Silverman AJ, Sutherland AK, Wilhelm R and Silver R: Mast cells migrate from blood to brain. J Neurosci 20: 401-408, 2000 . 